The leucocytosis and recurrent fever were misleading in suggesting a possible chronic infection. It is noteworthy that Campbell (1964) has suggested that a familial disease described by himself and Clifton (1950), thought to be toxoplasmosis and showing features such as chronic rash, leucocytosis, fever, pes cavus, nerve deafness, and choroido-retinitis, might in fact be another example of familial amyloidosis.

Though our patient was born on the border of Derbyshire, all attempts to trace his relatives and any connexion with the Derbyshire family described by Muckle and Wells have failed. Despite this, we believe that the patient was an example of hereditary amyloid nephropathy.

\section{Total Central Retinal Artery Occlusion Successfully Treated}

Brit. med. F., 1966, 1, 32

Many patients have recovered useful vision after occlusion of the central retinal artery. However, the great majority have shown evidence of retaining considerable retinal circulation during the period of obstruction. Recovery after an effectively total obstruction, as evidenced by absence of light perception, is rarer.

The treatment of such cases is therefore urgent, and it is unlikely that a single therapeutic manœuvre will be found generally effective in treating the condition. Hardenbergh (1962) successfully treated a case of idiopathic central retinal artery occlusion by repeated ocular massage, inspiration of $10 \%$ carbon dioxide and $90 \%$ oxygen, the administration of intravenous acetazolamide, and the retrobulbar injection of a vasodilator, procaine, with hyaluronidase. Leffertstra (1962) treated a case with intravenous Priscol (tolazoline), followed by oral nicotinic acid and Nepresol (dihydrallazine sulphate). Simmonds (1962) treated his case with paracentesis and nicotinic acid, and the vision was restored with only a small residual paracentral scotoma. For such treatment to be effective it is imperative that it should be instituted as soon as possible. If the anaemia exists for only an hour or so central vision may return. It is usually considered that treatment is unlikely to be effective if it is delayed for longer than five and a half hours, though exceptionally it may still be effective after a lapse of some days (Werner, 1913).

\section{CASE REPORT}

A 60-year-old man reported on 20 May 1964 with a sudden and complete loss of vision in his left eye which had occurred an hour before.

Ocular examination revealed a visual acuity in the right eye of $6 / 6$. In the left eye there was perception of light only on the nasal aspect of the retina. The pupil of the affected eye was semidilated and fixed (amaurotic). Ophthalmoscopic examination showed a typical central retinal artery occlusion in the left eye, with milky grey oedema in the macular area, a "cherry red" foveal spot, and greatly attenuated arteries.

Seventy-five minutes after the onset he was given a retrobulbar injection of $100 \mathrm{mg}$. of acetylcholine, ocular massage, and inspiration of $90 \%$ oxygen and $10 \%$ carbon dioxide (from an anaesthetic trolley). An intravenous injection of $500 \mathrm{mg}$. of acetazolamide was also given. This was followed 30 minutes later by paracentesis of the left eye. The following morning the left pupil was reacting briskly to light, and he was put on tab. nicotinic acid $50 \mathrm{mg}$. four
We wish to thank Professor C. E. Dent, Dr. O. G. Dodge, and Dr. A. Jordan for their help with this case.

$$
\text { D. D. KENNEDY, M.B., CH.B., }
$$

Registrar in Chemical Pathology, Sheffield Royal Infirmary. F. D. RosenTHAL, M.B., B.S., M.R.C.P., M.D., Consultant Physician, Leicester General Hospital.

I. B. SNEDDON, M.B., CH.B., F.R.C.P., Consultant Dermatologist, Sheffield Royal Infirmary.

\section{REFERENCES}

Campbell, A. M. G. (1964). Lancet, 1, 220.

Gafni, J., Sohar, E., (1950). Brain, 73, 281.

Gafni, J., Sohar, E., and Heller, H. (1964). Lancet, 1, 71.
Muckle, T. J., and Wells, M. (1962). Quart. F. Med., 31, 235.

times a day and tab. Priscol $25 \mathrm{mg}$. three times a day. All these measures were instituted to cause speedy vasodilatation.

On the third day after the onset of blindness the vision in the left eye returned to $6 / 9$ and the central fields showed no central or paracentral scotoma, but only small scattered segmental defects in the upper half of the field between $20^{\circ}$ and $25^{\circ}$ from the fixation spot. Five months later, however, the eye showed a small paracentral scotoma in the upper nasal quadrant of the central field between $5^{\circ}$ circle and the fixation spot and the peripheral segmental defects disappeared. This is now the final residual field defect.

In an attempt to establish the cause of the condition the patient was referred to the Medical Unit of the Royal Alexandra Infirmary. The report was as follows: "Cardiovascular examination showed a loud first sound at the base and a fairly harsh systolic murmur radiating to the axilla. No diastolic murmur was heard, though the character of the first sound suggested mitral stenosis. Bloodpressure was $150 / 85 \mathrm{~mm} . \mathrm{Hg}$ in the right arm and $154 / 88 \mathrm{~mm} . \mathrm{Hg}$ in the left arm. Urine was green to Clinitest, fasting blood sugar was $69 \mathrm{mg} . / 100 \mathrm{ml}$., serum cholesterol was $310 \mathrm{mg} . / 100 \mathrm{ml}$. Electrocardiography showed no abnormality, chest $x$-ray and cardiac screening showed no cardiac abnormality, lung fields showed some inflammatory changes. Carotid angiogram was not considered necessary at this stage. This could well be an embolic phenomenon in the left eye of cardiac origin."

The patient, however, was not put on anticoagulants. When last seen this year he still had $6 / 9$ vision in the left eye and the same field defect, and his general health was very good.

\section{Comment}

It may be argued that this patient has had too many therapeutic procedures carried out on him. As stated previously, a single therapeutic measure is unlikely to be successful unless the obstruction is partial or is of 10 to 15 minutes' duration. An emergency like central retinal artery occlusion frequently requires desperate therapeutic measures. In this case the total occlusion was of an hour's duration, and I think the multiple therapy was justified in view of the end result of $6 / 9$ vision and a small residual paracentral scotoma.

I would like to thank Dr. S. G. McAlpine, Consultant Physician, and $\mathrm{Dr}$. T. Parsons for their help in investigating this patient at the Medical Unit of the Royal Alexandra Infirmary, Paisley.

M. A. NANJIANI, M.B., B.S., D.o., D.o.M.S.

Royal Victoria Eye Infirmary, Paisley.

\section{REFERENCES} Hardenbergh, F. E. (1962). Arch. Ophthal., 67, 556. 43. Leffertstra, L. J. (1962). Ophthalmologhthal., 54, 1129. Simmonds, N. T. (1962). Amer, F. (1913). Trans. ophthal. Soc. U.K., 33, 9. 